clinical interests, needs bringing up. I am a firm adherent of the policy of the salient, but the extent to which we bring up the line is the measure of our consolidation in the confidence of the profession and the esteem of the whole community.

\section{MATERNAL MORTALITY AND MORBIDITY.*} BY

LOUISE McILROY, M.D., CH.B.,

PROFESSOR OF OBSTETRICS AND GYNAECOLOCY, LONDON SCHOOL OF MEDICINE FOR WOMEN.

'THE passing of the Midwives Act in 1902 was an epochmaking event. I hope that the two reports-that by Dame Janet Campbell; issued by the Ministry of Health, and that by the Scottish Committee-will lead to other reforms of almost equal importance. In 1923 living births numbered 758,131 and maternal deaths 2,892 , or 3.81 per 1,000. Of these, puerperal sepsis accounted for more than one-third, and eclampsia for one-ninth, so that deaths from other causes were 1,552, or about 2 per 1,000. But, as every practitioner knows, these fig:rres do not tell the whole story. They do not indicate the terrible amount of ill health due to pregnancy, much of which is avoidable. I. cannot, however, acquiesce in the opinion that the profession is entirely to blame. Until a comparatively recent date education in midwifery was meagre, and the practitioner, when qualified, was not as well equipped as he might have been to deal with midwifery. It redounds to the (redit of the general practitioner that in most cases the refective education has been effectively supplemented by observation and practical experience. If the British accoucheur be compared with those in other countries it will probably be found that he is the best; for reasons which influence Dame Janet Camplell I place small reliance on comparative international figures.

In considering the progress of midwifery and the credit due to those engaged in its practice, wo must remember that the fall in the infantile mortality rate from 154 in 1900 to 77 in 1922 is due in no small measure to improved obstetrics, by means of which hundreds of thousands of mothers have been enabled to produce healthier children. This is so even in spite of the stationary mortality of the first month. It may also be pointed out that the comparison letween the general death rate and the maternal mortality rate may be fallacious, as it cloes not foliow that there was the same room for improvement in the latter. We know, for example, that there was a great wastage of infant lives which should have been preserved, and the saring of these has been chiefly responsible for reducing the general death rate. There is no evidence of any such preventable wastage in maternal lives.

As concerns morbidity, it is not possible to compare one period with another. There is, however, good reason for belicring that morbidity has decreased and is steadily decreasing. Progress may not be as rapid as we desire, but if our efforts have not been successful in reducing morbidity it is obvious that our methods must be radically wrong. It must, however, be admitted that maternal mortality and morbidity are partly due to ignorance, carelessness, and undue haste on the part of doctors and midwives. The cases quoted in Dame Janet Campbell's report make sad reading, but they represent only a minute fraction of a vast total of midwifery. Other branches of the profession have their inefficient followers, but it is casier to detect obstetrical errors. We can only look to improved education and the inculcation of higher ideals to remedy these evils. In other directions also there is much to be tlone. Maternal mortality and morbidity are no cloubt largely influenced by had housing and economic or inclustrial conditions. This, howerer, is not the place to deal with those questions. I propose to confine myself to the medical points.

rirst. I look to the extension of ante- and post-natal work as the most effective means of improvement. There is no need to dilate on the adrantages of ante-natal ${ }^{*}$ A paper (slightly abridged) read in opening a discussion in the Mortality, published in the S'PpLEMtis of January 9th, 1906. examinations and treatment, but it may be well to urge the importance of "after-care" in the interests of both mother and child. The continuance of breast-feeding is most important, and this cannot be ensured unless the mother is kept under the observation of the obstetrician $f_{o r}$. at least a month after the child is born. The post-natal (or rather the maternal and neo-natal) clinic also affords the means of studying and rectifying injuries and other illnesses due to labour. Ante- and post-natal clinics should not be confused with child welfare, and should be staffed br practitioners experienced in obstetrics. No person (ain cary out ante-natal work who has not been trained. It is a very difficult branch of medicine, and requires much skill and judgement in diagnosis. An intensive campaign should be organized to teach people the advantages of antenatal work, which can be demonstrated by simple examples. For instance, toxaemia can be controlled or avoided and eclampsia almost eliminated by early recognition and appropriate treatment. The risks of labour in cases of pelvic abnormality may also be obviated or reduced. Stejs must be taken to improve and extend the teaching of antrnatal methods for the benefit of both medical students and pupil midwives.

Second. While education in midwifery has improved, mich remains to be done. For instance, one great defert is the absence of any clinical test at tho final examination. But above all we must have facilities for post-graduate training of young practitioners and for refresher courses for older ones. We do not want more lectures, but facilitics for clinical work and the actual handling of patients unde: the supervision of competent teachers. For this purpose wo require one or more well equipped maternity hospitals, solely devoted to the instruction of graduates and staffed by experts who would serve only for limited periods, so as to give persons attending for instruction opportunities for studying different methods. It is sad to think that, considering all the material available in this country, anyone desiring instruction of this sort should have to go to Vienna or Paris. As 60 per cent. of the deliveries in this country are made by midwives, it is most essential that their education also should be improved by increasing clinical facilitic. that will cuable them to see and take part in practical obstetric's of the best type.

Third. The provision of more beds for abnormal cases and $f_{0}$ women who desire institutional accommodation owing to housing difficulties. The material thus provided could be utilized for educational purposes.

Fourth. We now come to that mysterious subject sepsis, of which, though it is a notifiable disease, there is no workable definition. At the same time, generally speaking, we know only too well the class of symptoms which come under this name. Wo also know, partially at any rate, the cause. We know that sepsis may be contagious and exogenous, and that to a great extent it may be avoided by cleanliness. On the other hand, we are satisfied that sepsis is also endogenous, but we do not understand how it arises in these circumstances. In the time at my command I cannot discuss technical details. I may say, however, that there is every reason to believe that streptococci that may be harmless when living upon a healthy unbroken epithelium change their character and become dangerous whei allowed to feed on a bruised or broken surface. There are other possible causes of sepsis demanding investigation, notably the cffect of intercourse during the later months of pregnancy and the after-effects of venereal disease. We are also faced with the strange and inexplicable fact that women who live and have their children in dirty surroundings do not suffer more from sepsis than those who live and have their children under the best possible conditions. Both classes suffer from contagion, but it is questionable whether the former class is not less liable than the latter, provided no operative intervention has been carried out. When we come to the endogenous type, either there is no difference between the two classes, or if there is a difference it is in favour of the women who live and have their children under apparently unfavourable conditions. All this requires elucidation, and more factities for research are necessary-iesearch especially directed towards immunity and the defensive nature of the bacteria of the genitail tract. The course and treatment of sepsis we understand 
fairly well. What we want to know is the cause of the endogenous variety. If this could be discovered we might reduce maternal mortality by one-third. This is an object upon which expenditure is worth while. The saving of 1.100 women's lives is no small matter.

Fifth. The existing organization of midwifory is more or less chaotic, and there is a lack of cohesion between the local authorities on the one hand and medical practitioners and midwives on the other. The midwife can call in any doctor she thinks fit. He may be experienced or may not, and there is no adequate supervision by the medical profession of the midwiferr service as a whole. Panels of medical practitioners specially experienced in midwifery should be set up, and except in cases of cmergency the midwives should be restricted to the members of these panels. Each patient should be seen by a medical practitioner at least once during her pregnancy. There should also be attached to every panel one or more specialists whose opinion could be songht in ases of exceptional difficulty. Every case of death in rhildbirth should be reported and investigated, so as definitely to ascertain the rause and whether the treatment has been as it should. Ante- and post-natal clinies and child welfare clinies should be co-ordinated. More beds shonld be provided for difficult cases, and arrangements made to pass on from the antenatal clinics those women whose confinements are likely to be difficult. Cases of sepsis should not be treated in fever hospitals, but in open-air isolation wards of maternity lospitals.

That the mortality rate is exceptionally high in sparsely populated districts proves the advantages of skilled and prompt attendance. Steps should be taken to remedy these conditions by a more comprehensive system of administration; and here again the ralue of ant?-natal work is apparent. If every expectant mother were to present herself for ante-natal examination by a medical practitioner, arrangements could be made, even in sparsely populated arcas, to provide her with the necessary assistance.

In conclusion, let me say that there is no occasion for despondence, but every reason for hope. Statistics are dangerous things. For instance, the Scottish figures are most depressing, showing as ther do that deaths from puerperal causes in Scotland have increased since 1855 from 4.9 to 6.2 per 1,000 births. I do not believe that these figures accurately show the state of affairs. I cannot believe that more women die from childbirth to-day in Scotland than in 1855 . These figures depend on classification and knowledge on the part of the medical attendant. Fren in an obstetric hospital we find it difficult to tabulate the diseases of pregnancy, notwithstanding an elaborate system of cross-indexing. This applies particularly to venercal diseases.

These matters demand urgent practical attention. Whatcver eriticism there may be on either side, we all have the same object in view. We are all anxious to improve the niidwifery service and to save human lives.

\section{THE TRE ITNENT OF SEVERL ANI) PERSISTENT UTERINE HAENORRHAGE BY RADIUY. With a Report of 200 Cases.}

SIDNEY FORSDIKE, M.D., B.S., F.R.C.S., SLRGEON TO OUT-PATIENTS, SOHO HOSPITAL; GYNAECOLOGICAL SURGEON TO KENSINGTON GENERAL HOSPITAL.

'THE type of haemorrhage under consideration is frequently described as idiopathic or essential haemorrhage, and pathologically it is referred to as chronic metritis, fibrosis nteri, or chronic subinvolution; but, however debatable the pathology, the one distinctive feature is the excessive and uncontrollable haemorrhage with absence of any pelvic lesion to account for it. This series of cases does not include the minor uterine haemorrhages which are relieved by drugs or a single curettage, but only cases which had been dealt with in the ordinary way and proved refractory. In many of the cases I have myself porformed curettage in the hope that it would alleviate the condition, and only used radium when it was subsequently found that the operation had had little or no effect. 'The cases. Were chosen for the following reasons:

(1) The persistence of uterine haemorrhage after proionged medical treatment.

(2) After curettage or other operation with no relief.

(3) Adranced degree of anaemia, with shortness of breath, headaches, oedema of the legs, etc.

(4) Cases in which the patient had to spend some piat of each month in bed on account of the sercrity of the hamorrhage.

Analysis of this scries of 200 cases shows the following reasons for tho troatment:

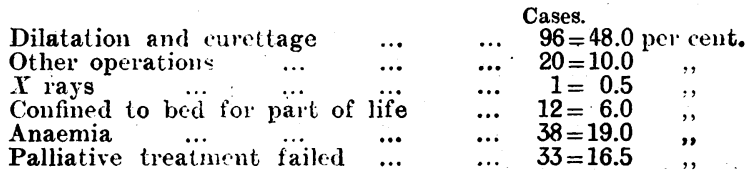

A large number ( 48 per cent.) had already been treated by dilatation and eurettage, of which 8 had been curetted twice, 4 three timos, and 2 five times. Blacker ${ }^{1}$ records a case where the patient har been curetted eighteen timcis. It seems havdly credible that this operation could be repeated four, fire, and more times; nevertheless it is frequently done. It is reisonable to repeat it once where a patient has derived considerable benefit from it fo: months and is nearing the menopause, but there ant he little reason for pursuing it beyond this point.

Twenty ases had undergone some other form of operative treatment, including excision of polypi, ampur::tion of the cervix, resection of cystic ovaries, vontinl suspension, salpingectomy, appendicectomy, and myomertomy-the best resilts being relief for a few monthic aml the poorest no relief : at all. One patient (Case 5) hal been curetted, and, this proving of no avail, was $\left.\leqslant u^{\prime}\right\}$ sequently given fire exposures of $x$ rays, the detrits of which I did not learn; she improved for a few monthi, relapsed, and was then successfully treated by jadium.

Twelve cases $(6$ per cent.) were almost completely hedridden, and spent the greater part of their time betwons bed and a couch.

Thirty-eight cases (19 per cent.) were in an adranced degree of anaemia through continuous loss. One (Case 17) had been treated palliatively and later by curettang; after the operation the bleeding did not stop and she was becoming seriously ill. The surgeon had had her prepared for hysterectomy, but as I was in the hospital that morning treating another case he asked me to see her. We decided to give her the chance, and radium treatment was carried out. After one exposure temporary relict occurred, and five months later a second exposure was given, which established amenorrhoea permanently.

Case 66.-This patient, aged 18, had been an in-patient and out-patient at a general hospital for sixteen months, but the continued to lose excessively $\frac{8-10}{14-21}$. This was aggravated $1 \cdot y$ intermenstrual loss, and culminated in a five weeks' continuous and severe haemorrhage. She was seen at her home in consultation by one of $\mathrm{my}$ colleagues, and immediately sent to hospital in an ambulance. She was colourless, breathless, and hospital in an ambulance. She was colourless, breathess, and looked to be in a moribund state. A blood count showed-
red blood cells, $2,200,000$ per c.mm.; white cells, 12,000. She was red blood cells, $2,200,000$ per c.mm.; white cells, 12,000. She was
given $100 \mathrm{mg}$. of radium bromide for twenty-four hours. Ameno:given $100 \mathrm{mg}$. of radium bromide for twenty-four hours. Amenor-
rhoea ensued for three months; then she had irregular periods rhoea ensued for three months; then she had irregular periods
of five-day type for five months, and then became, and remains, regular every four weeks of the five-day type. This patient hrd what is known as the haemorrhagic diathesis, for extraction of a tooth was followed by troublesome haemorrhage and the socket required repeated plugging; she bruised very easily, but no gooss required repeat phos during her period of amenorrhoea she had attacks of epistaxis.

\section{IIistory.}

This condition may occur at any period of menstrual life, but is more commonly found at and around puberty, between 30 and 40 years of age, and at the menopause. The clinical picture is that of menorrhagia and metrorrhagia, and the period may be so prolonged that the patient finds it easier to describe how many days in the month she is clear, rather than to describe how long the haemorrhage lasts. Finally, she may have to sperid most of her time in bed on account of the haemorrhage and consequent anaemia. 